Article

\title{
Hybrid Nanosecond Laser Processing and Heat Treatment for Rapid Preparation of Super-Hydrophobic Copper Surface
}

\author{
Linxu Ma ${ }^{1}$, Lina Wang ${ }^{1}$, Chengying Li ${ }^{1}$, Jian Guo ${ }^{2}$, Pranav Shrotriya ${ }^{2,3,4}$, Cui Deng ${ }^{2}$ and \\ Jingnan Zhao $2,3, * \mathbb{D}$ \\ 1 Mechanical Engineering Department, Tianjin Sino-German University of Applied Sciences, Tianjin 300350, \\ China; malinxu@tsguas.edu.cn (L.M.); wanglina@tsguas.edu.cn (L.W.); lichengying@tsguas.edu.cn (C.L.) \\ 2 College of Mechanical Engineering, Tianjin University of Science and Technology, Tianjin 300222, China; \\ arow@mail.tust.edu.cn (J.G.); shrotriy@iastate.edu (P.S.); dc517985@163.com (C.D.) \\ 3 Tianjin Key Laboratory of Integrated Design and On-Line Monitoring for Light Industry \& Food Machinery \\ and Equipment, Tianjin 300222, China \\ 4 Department of Mechanical Engineering, Iowa State University, Ames, IA 50011, USA \\ * Correspondence: jingnanzhao@tust.edu.cn; Tel.: +86-13920614682
}

Received: 15 May 2019; Accepted: 6 June 2019; Published: 9 June 2019

\begin{abstract}
The super-hydrophobic copper surface was obtained by using a nanosecond pulsed laser Different micro- and nano-structures were fabricated by changing the laser scanning interval and scanning speed, before heating in an electric heater at $150{ }^{\circ} \mathrm{C}$ for two hours to explore the effect of laser parameters and heat treatment on the wettability of the copper surface. It was found that the laser-treated copper surface is super-hydrophilic, and then, after the heat treatment, the surface switches to hydrophobic or even super-hydrophobic. The best super-hydrophobic surface's apparent contact angle (APCA) was $155.6^{\circ}$, and the water sliding angle (WSA) was $4^{\circ}$. Super-hydrophobic copper is corrosion-resistant, self-cleaning, and dust-proof, and can be widely used in various mechanical devices.
\end{abstract}

Keywords: nanosecond laser; super-hydrophobic copper surface; micro- and nano-structures; apparent contact angle; sliding angle

\section{Introduction}

Bionics is the application of biological methods found in nature to the study and design of industry materials and advanced technologies. There are many animals and plants in nature that have this kind of function, such as the lotus leaf, bird feathers, butterfly wings, and so on. This paper focuses on the super-hydrophobic phenomenon (wettability). Wettability can be measured by apparent contact angle (APCA), which is the angle between the outline of the liquid (water in this case) surface and the contact material surface (solid surface typically) [1,2]. A super-hydrophobic surface refers to an APCA greater than $150^{\circ}$, and a water sliding angle (WSA) less than $10^{\circ}$ (low contact-angle hysteresis). It is waterproof and self-cleaning; thus, it is not only an interesting phenomenon in nature, but also of great scientific interest. In recent years, the super-hydrophobic phenomenon was widely used in environmental purification, food packaging, medical devices, etc. [2-7].

Many studies showed that there are many factors affecting the material surface's super-hydrophobicity, including surface energy and roughness; in particular, rough nano-structures highly influence the wettability of the material surface. Therefore, the present preparation methods of super-hydrophobic materials mainly focus on the material surface roughness and surface modification. 
In order to find the best super-hydrophobic metal surface, we should know the reasons behind certain materials being super-hydrophobic.

A dense column micro- or nano-structure is the key factor causing a super-hydrophobic surface. Thus, when we look for a super-hydrophobic surface, micro- and nano-scale dense column structures, such as the microstructures of lotus leaves, bird feathers, and butterfly wings, are considered. Although there are many ways to fabricate the hybrid micro/nano-structure on the material surface, such as chemical vapor deposition, chemical etching, nano-imprint lithography, electrode position, etc., there are various problems in their application [8-17]. For example, the size of the micro/nano-structure formed by the chemical etching method is very sensitive to external conditions such as temperature and concentration of chemical solution. In addition, etching reagents are mostly corrosive reagents with safety and environmental issues. Unlike the above methods, lasers can fabricate and precisely control the size of micro/nano-structures [18-23]. Therefore, laser processing can be used to quickly obtain micro/nano-structures. Recent studies found that the surfaces of metal oxides and nanostructures formed by laser ablation are initially hydrophilic or even super-hydrophilic; however, over time, they become hydrophobic, and sometimes even super-hydrophobic in air after two weeks to two months [24]. Several mechanisms were proposed to explain this phenomenon. Chang et al. proposed that the deoxidation of copper oxide could effectively promote the development from a hydrophilic to a super-hydrophobic surface $[25,26]$. Boinovich et al. believed that metal oxides adsorbed organics in the air, resulting in the transition from a super-hydrophilic to super-hydrophobic surface $[27,28]$. It can be seen that, although most researchers extensively studied this topic, there is obvious controversy regarding the mechanism of the wettability transition behavior.

In this paper, a rapid method of fabricating a super-hydrophobic surface on a copper plate was studied. Micro/nano-structures were fabricated on copper surfaces by laser ablation, which then became super-hydrophobic after heat treatment. The mechanism of wettability transformation was investigated, and a fast method to prepare super-hydrophobic surfaces was studied. In addition, the effect of the laser parameters on the surface wettability of copper plate was investigated. The results indicate that the laser scanning interval and scanning speed are the key factors for producing the copper super-hydrophobic surface.

\section{Materials and Methods}

\subsection{Materials}

Copper samples (purity 99.9\%-supplied by the Beijing nonferrous metal research institute) were cut into $10 \times 10 \times 0.5 \mathrm{~mm}^{3}$ pieces, followed by ultrasonic cleaning in acetone and deionized water for $10 \mathrm{~min}$ to remove impurities and any oil remaining on the surface.

\subsection{Laser Ablation Treatment}

The copper samples were ablated by nanosecond laser (HANS laser EP-20-SHG, Han's Laser, Shenzhen, China) with a wavelength of $532 \mathrm{~nm}$ and a spot size of $20 \mu \mathrm{m}$. In the experiment, the laser processing was carried out by scanning with a grid pattern (line-by-line in both horizontal and vertical directions with varying distances between adjacent scanning lines), as shown in Figure 1. In the process, different micro/nano-structures were formed on the machining surface by changing the scanning speed $V(100,500,900,1300,1700 \mathrm{~mm} / \mathrm{s})$ and scanning interval $h(0.005,0.01,0.015,0.02 \mathrm{~mm})$, as shown in Table 1. 
Table 1. Laser processing parameters.

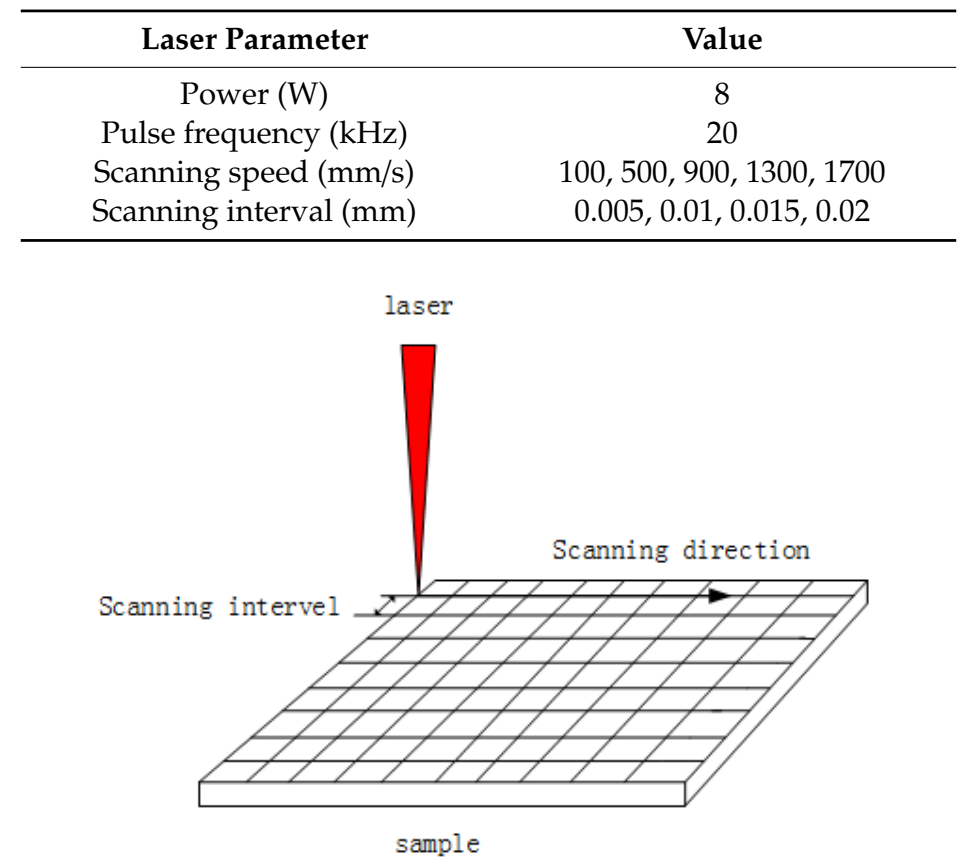

Figure 1. Grid pattern scanning.

\subsection{Heat Treatment}

The laser-treated sample was placed in a heater with a temperature of $150{ }^{\circ} \mathrm{C}$ for $2 \mathrm{~h}$ (tempering) as post-treatment to change its wettability. Vacuum or non-vacuum tempering environments were set to investigate the effects of oxidation and organic matter in the air on the surface wettability of samples.

\subsection{Characterizations and Tests}

The morphology of the sample was observed by field-emission scanning electron microscopy (FE-SEM, FEI, Hillsboro, OR, U.S.A.), and the crystal structure of the sample was analyzed by X-ray diffraction (XRD D8 Advance, Bruker, Karlsruhe, Germany). The surface chemical composition was analyzed by energy-dispersive X-ray spectroscopy (EDS, FEI, Hillsboro, OR, U.S.A.). The wettability of the sample was evaluated by measuring APCA and WSA with an automatic contact-angle measuring instrument (Zhongchen JC2000DM, Beijing Zhongyi, Beijing, China). The values of APCA and WSA on the surface of each sample were measured five times at random locations, and all measurements were made when the droplets reached a stable state.

\section{Results and Discussions}

\subsection{Morphology}

FE-SEM images of the laser- and heat-treated copper surfaces are plotted in Figure 2. As can be seen from Figure 2a,c,e, the laser grid scanning formed regular grid micro/nano-structures. The periodic square formed on the surface of the copper plate was distributed along the horizontal and vertical directions by laser scanning. This is because the laser irradiation caused the temperature of the copper surface to rise to its melting point, whereby the surface material melted and evaporated. In the laser processing process, the nanoparticles still remained on the surface after laser irradiation, thus forming the nanostructure (shown in Figure 2b, numbered 2). The size, shape, and distributions of nanoparticles largely depend on the laser fluence and the scanning interval. As shown in Figure 2a,b, when the scanning speed and scanning interval were small (more laser energy absorbed by surface), a large number of slender columnar structures appeared on the surface of the copper plate, with 
some gully structures among them. As shown in Figure $2 b$, it can be observed that the size of these slender columnar structures ranged between 8 and $20 \mu \mathrm{m}$, and they were uniformly distributed on the surface. Figure 2c,d show that, when the scanning interval was constant, with the increase of scanning speed, the array of obvious columnar structures was distributed to form micro-square elements, and micro-grooves with nano-particle deposition were formed at the boundary of the slender columnar structures, resulting in the adjacent gully structures becoming more obvious. In a further magnification, it can be observed that the columnar structure was about $30 \mu \mathrm{m}$ in size, the gully spacing became larger, and the period was about $50 \mu \mathrm{m}$, as shown in Figure $2 \mathrm{~d}$. In addition, a large number of micro/nano-particles aggregated, which can be observed to be randomly attached on the micro-columnar surface. Therefore, with the increase of the laser scanning speed, the micro-columnar structure became larger, and the distribution changed from irregular to regular, whereas the columnar structure and gully became relatively flat. A similar structure appeared as the scanning interval increased. Compared with Figure 2c,d, when the scanning speed was constant and the scanning interval increased, it can be observed in Figure $2 \mathrm{e}, \mathrm{f}$ that micro-columnar structures and grooves gradually disappeared and some flat corrugated structures appeared. As shown in Figure 2b,d, in the larger magnification image, there were fine nano-scale particles randomly distributed on the surface, which increased the surface roughness of the material. By changing the laser processing parameters, various surface morphologies can be realized, which is essential to controlling the material surface wettability.
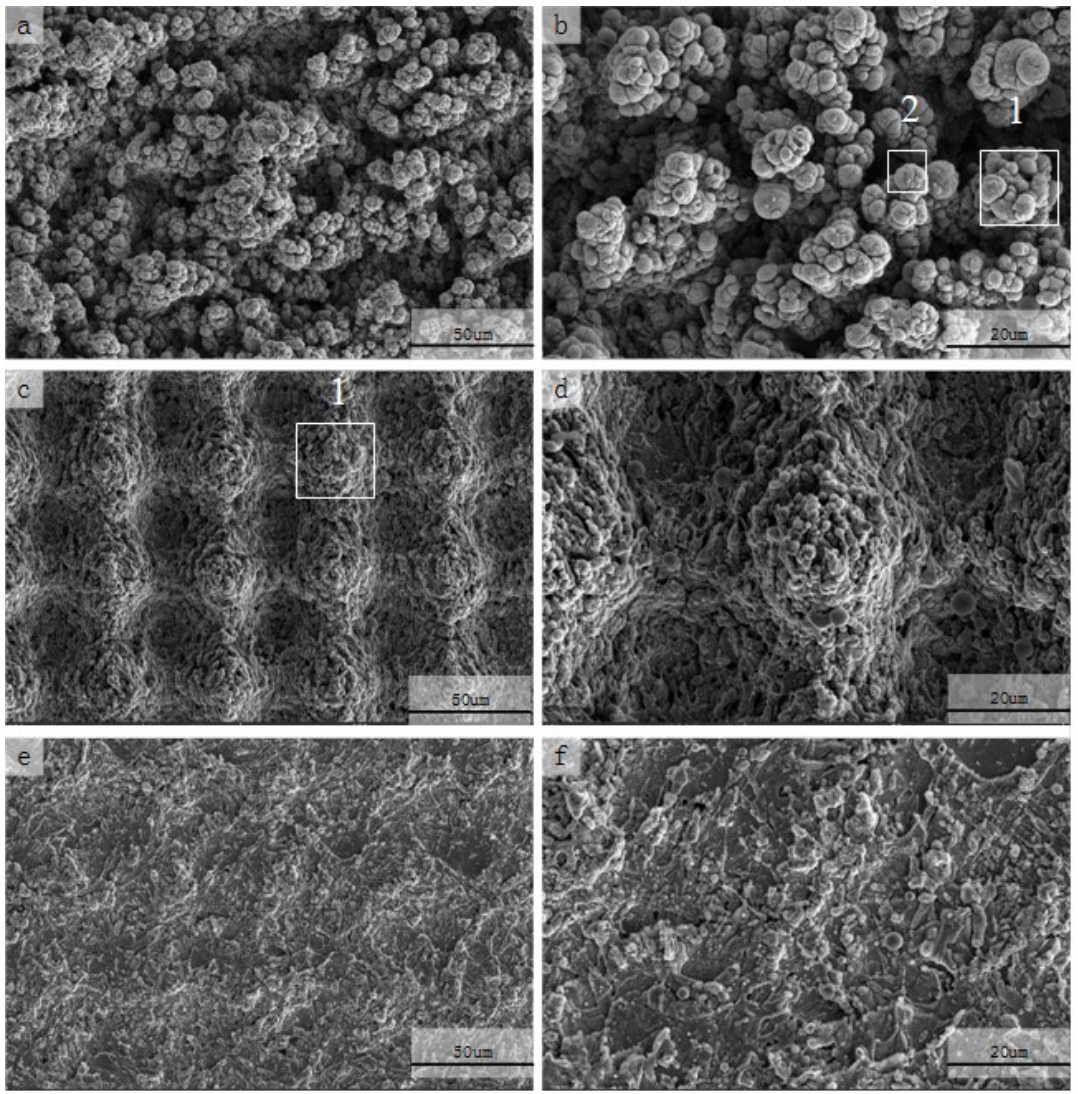

Figure 2. SEM image of copper plate surface after laser ablation and heat treatment: $(\mathbf{a}, \mathbf{b})$ scanning speed: $100 \mathrm{~mm} / \mathrm{s}$, scanning interval: $0.005 \mathrm{~mm}$; (c,d) scanning speed: $1300 \mathrm{~mm} / \mathrm{s}$, scanning interval: $0.005 \mathrm{~mm}$; (e,f) scanning speed: $1300 \mathrm{~mm} / \mathrm{s}$, scanning interval: $0.02 \mathrm{~mm}$. 1-nanostructures; 2-slender columnar structures.

In order to illustrate the relationship between the laser parameters and the surface microstructure, the three-dimensional (3D) contour map of the surface structure was tested. Figure 3a shows the 3D profile of a typical surface when the laser scanning speed was $100 \mathrm{~mm} / \mathrm{s}$ and the scanning interval 
was $0.005 \mathrm{~mm}$. The surface roughness (Ra) value of this structure was $15.7 \mu \mathrm{m}$, which is higher than other samples with different scanning speeds. As the scanning speed increased, the roughness value gradually decreased. As shown in Figure $2 \mathrm{~b}$, the surface Ra value was $4.9 \mu \mathrm{m}$, which is dramatically lower compared with Figure 3a. This reduction in roughness is consistent with the SEM observation that the surface topography became flatter and shallower as the scanning speed increased. In addition, Figure 3a,c show the relationship between surface roughness and scan interval. As shown in Figure 3c, when the scanning speed was $100 \mathrm{~mm} / \mathrm{s}$, and the scanning interval was $0.02 \mathrm{~mm}$, the surface Ra value was $4.7 \mu \mathrm{m}$. The surface roughness slightly decreased with the increase of scanning interval. This is because reducing the scanning interval also resulted in more complex and coarser structures. Therefore, the morphology of the surface can be tuned by simply adjusting the scanning speed.

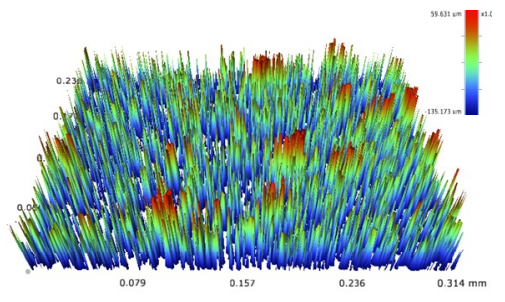

a

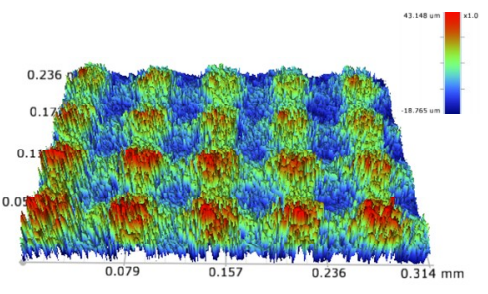

b

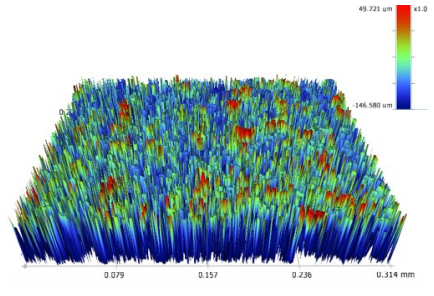

Figure 3. Three-dimensional (3D) profile of laser-ablated and heat-treated copper surfaces: (a) scanning speed: $100 \mathrm{~mm} / \mathrm{s}$, scanning interval: $0.005 \mathrm{~mm}$; (b) scanning speed: $1300 \mathrm{~mm} / \mathrm{s}$, scanning interval: $0.005 \mathrm{~mm}$; (c) scanning speed: $100 \mathrm{~mm} / \mathrm{s}$, scanning interval: $0.02 \mathrm{~mm}$.

\subsection{Wettability}

Compared with untreated copper surfaces (APCA of about $80-85^{\circ}$ ), the laser-treated copper surfaces were hydrophilic or even super-hydrophilic, with an APCA range of $5 \pm 1.2^{\circ}$ to $45 \pm 1.6^{\circ}$. Following the laser treatment and material tempering in the heater, all materials with the different tempering processes appeared to transition from super-hydrophilic to super-hydrophobic. As shown in Figure 4a, the surface APCA after heat treatment was measured. It can be observed that the APCA on the surface of the sample was in the vicinity of $150^{\circ}$. When the scanning interval was constant, the surface APCA decreased with the increase of scanning speed. When the scanning speed was constant, the surface APCA decreased with the increase of scanning interval. However, the APCA change was not obvious, as the maximum difference was only $8.8^{\circ}$. Therefore, it is difficult to measure the surface wettability from APCA only. Thus, WSA was introduced to estimate the wettability (Figure $4 b$ ). In order to study the influence of scanning speed on the wettability of samples, it can be observed from Figure $4 \mathrm{~b}$ that, when the scanning interval was constant, the WSA value of the surface increased with the increase of scanning speed. When the scanning interval was no more than $0.005 \mathrm{~mm}$, the maximum WSA on the surface of the sample was $6^{\circ}$, which means that the surface adhesion was very low, characterized as being super-hydrophobic. In addition, when the scanning speed was constant, the WSA of the sample surface increased with the increase of the scanning interval. When the scanning speed was less than $100 \mathrm{~mm} / \mathrm{s}$, the surface WSA was less than $10^{\circ}$, with a minimum value of $4 \pm 1.2^{\circ}$. With the increase of scanning speed and scanning interval, although the surface APCA change was not obvious, (maximum of $153.5 \pm 3.8^{\circ}$, minimum of $144.7 \pm 1.2^{\circ}$; only an $8.8^{\circ}$ difference), the surface WSA changed a lot, with a maximum value of $68.6 \pm 0.6^{\circ}$ and a minimum value of $4 \pm 1.2^{\circ}$, equating to a difference of $64.6^{\circ}$. This indicates that, with the change of laser parameters, the WSA of the laser- and heat-treated sample surface was mainly affected in terms of the change of surface adhesion. These results further indicate that the water adhesion on the sample surface can be significantly changed by adjusting the scanning speed and the scanning interval. In order to analyze the stability of laser-treated copper surface super-hydrophobicity, a storage time versus WSA and APCA test was conducted. Table 2 summarizes the evolution of APCA and WSA with storage time of samples after laser and heat treatment. It can be seen that, after the samples were placed in air for a 
period of time, the APCA showed a certain growth trend, whereas WSA decreased, and both tended to be stable when they reached the level of super-hydrophobicity. Some researchers found that the reason for this phenomenon is the influence of organic matter in the air [28]. Therefore, when the samples that reached super-hydrophobicity were placed in the air, their values of APCA and WSA tended to be stable, and their surface wettability did not change significantly.

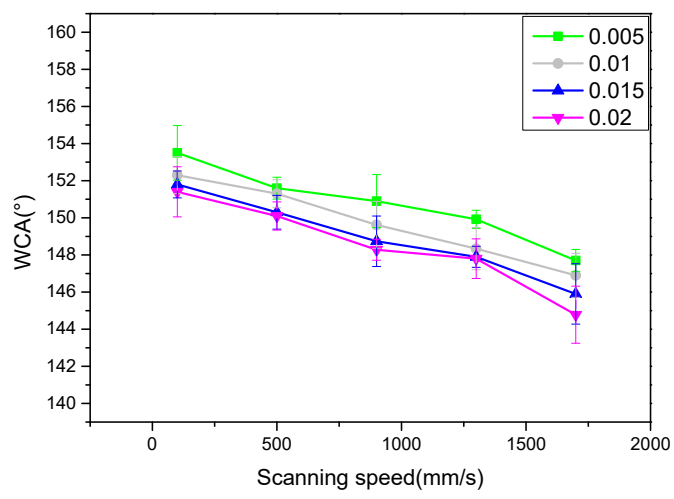

(a)

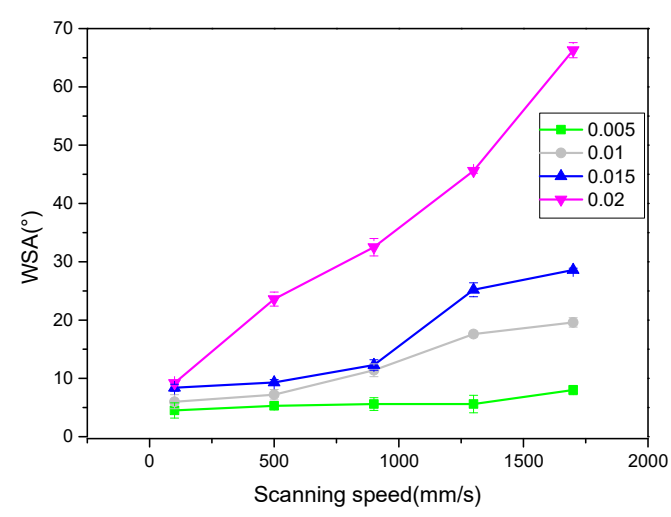

(b)

Figure 4. (a) Apparent contact angle (APCA) of laser ablation surface; (b) water sliding angle (WSA) of laser ablation surface.

Table 2. Evolution of apparent contact angle (APCA) and water sliding angle (WSA) measurements $\left(^{\circ}\right)$ with storage time.

\begin{tabular}{cccccc}
\hline Store Time & $1 \mathrm{~h}$ & 1 day & 10 days & 20 days & 30 days \\
\hline APCA $\left(^{\circ}\right)$ & $146.2 \pm 1.9$ & $147.2 \pm 0.9$ & $150.3 \pm 2.5$ & $154.3 \pm 2.1$ & $153.6 \pm 3.5$ \\
WSA $\left({ }^{\circ}\right)$ & $19.6 \pm 0.8$ & $14.5 \pm 1.9$ & $11.4 \pm 1.1$ & $8.2 \pm 0.9$ & $7.5 \pm 1.3$ \\
\hline
\end{tabular}

\subsection{Evaluation of Surface Composition}

To measure the chemical composition of the sample surface at each reaction stage and to determine the influence of the chemical composition on the surface wettability, the XRD test was conducted, and the results are shown in Figure 5 (the scanning interval was $0.005 \mathrm{~mm}$ and the scanning speed was $100 \mathrm{~mm} / \mathrm{s}$ ). It can be observed that the laser-ablated samples without heat treatment appeared as copper oxide $\left(2 \theta\right.$ angle of $\left.35.9^{\circ}\right)$, which was not shown in the untreated copper plate. The sample processed by both laser and heat treatment exhibited a new wave peak at $36.74^{\circ}$ ( $2 \theta$ angle), indicating the formation of cuprous oxide. To further confirm the element composition of the sample surface, EDS (only qualitative analysis was carried out here to observe the change trend of some elements in different treatment stages of the samples) tests were conducted on the sample. As shown in Table 3, there was a small amount of carbon on the laser-treated surface. The carbon came from the organic matter adsorbed from the air during the laser ablation and tempering processes. The carbon content of the laser-ablated sample did not change significantly after it was placed in air for a period of time $(24 \mathrm{~h})$. However, the carbon content and oxygen content on the sample surface increased obviously after tempering. This result indicates that the adsorption rate of organic compounds in the air was relatively low when the samples were placed in air after laser ablation. The surface carbon content of samples increased obviously after heat treatment, indicating that heat treatment accelerated the adsorption of organic compounds in the air. Some researchers believe that the wettability of the laser-treated copper plate changed when it was placed in air for a period of time, caused by the adsorption of organic matters in the air by oxides on the surface of the copper plate $[27,28]$. Therefore, the $\mathrm{C} / \mathrm{Cu}$ value can be used to measure the amount of adsorbed organic compounds. As shown in Figure 6a,b, the variation 
trend of $\mathrm{C} / \mathrm{Cu}$ value of different samples was consistent with that of the APCA. Note that the C/Cu ratio of samples with a large APCA was often larger. The increase in surface carbon content of metal oxides in ambient air was also reported in several published papers [28]. Therefore, it could be concluded that the increase of surface APCA of copper after heat treatment was caused by the adsorption of organic compounds, and the heat treatment process accelerated the adsorption of organic compounds.

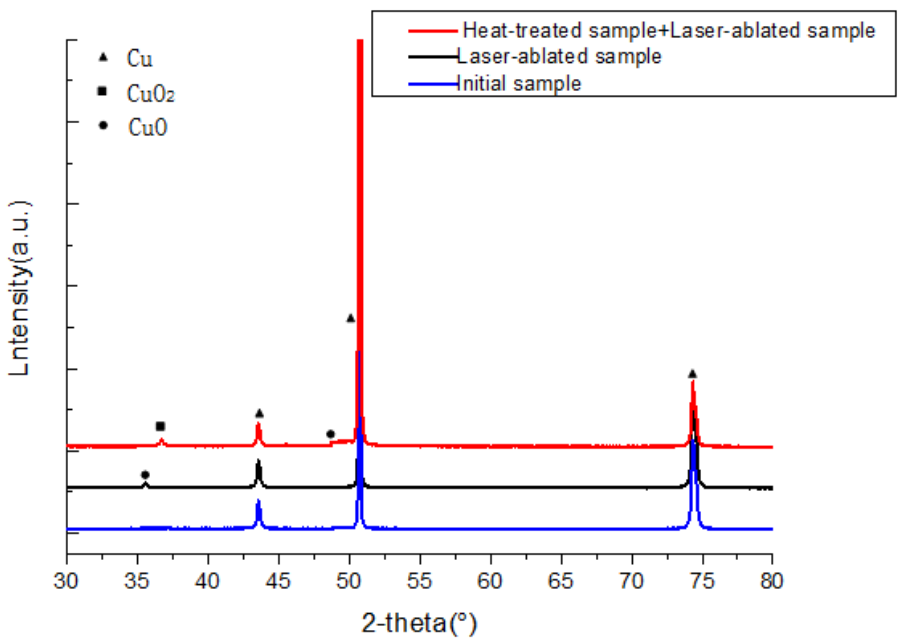

Figure 5. X-ray diffraction (XRD) results for initial sample, laser-ablated sample, and heat-treated sample.

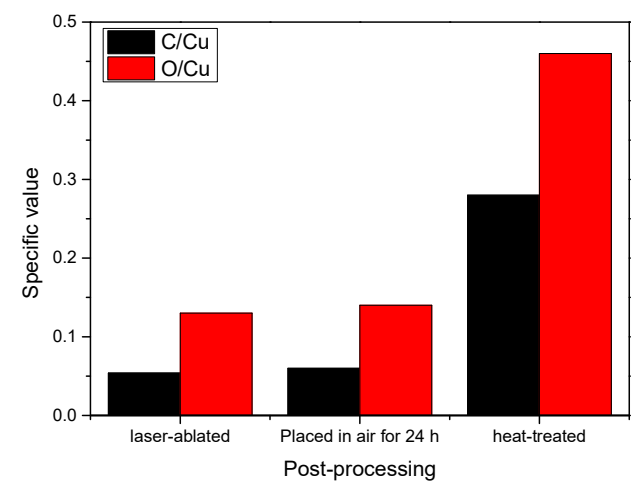

a

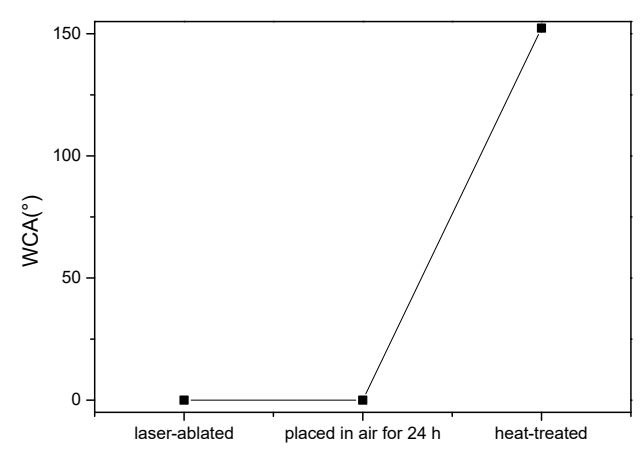

b

Figure 6. (a) The atomic ratio of $\mathrm{C} / \mathrm{Cu}$ and $\mathrm{O} / \mathrm{Cu}$ on the surface at different stages; (b) apparent contact angle of different stages.

Table 3. Energy-dispersive X-ray spectroscopy (EDS) results.

\begin{tabular}{cccc}
\hline \multirow{2}{*}{ Post-Processing } & \multicolumn{3}{c}{ EDS (\%) } \\
\cline { 2 - 4 } & $\mathbf{C u}$ & $\mathbf{O}$ & $\mathbf{C}$ \\
\hline Laser-ablated only (A) & $72.78-84.46$ & $10.96-16.02$ & $4.59-11.21$ \\
Laser-ablated and then placed in air for 24 h (B) & $71.34-83.36$ & $11.43-17.26$ & $5.09-12.21$ \\
Laser-ablated plus heat-treated (C) & $57.57-72.5$ & $18.55-26.44$ & $8.9-15.99$ \\
\hline
\end{tabular}

\subsection{Discussion}

The laser-ablated copper plate was hydrophilic, and the Wenzal model was introduced to explain the behavior of water droplets on the rough surface [29]. The Wenzel model indicates that the surface roughness has a positive effect on material surface wettability for both hydrophilic and hydrophobic surfaces. The sample surface forms micro/nano-structures when laser-ablated, and this rough laser 
texture surface shows hydrophilicity or even super-hydrophilicity. Moreover, for solid surfaces, an important characteristic that determines a material's affinity for water molecules is surface polarity; an increase in polarity usually leads to an increase of surface hydrophilicity. It is well known that most metal oxides are polar, and copper oxide has a large number of polar sites on its surface, thus forming a hydrophilic surface. For example, previous studies showed that hydroxyl groups on oxide surfaces reduce wettability by reducing the polar component of surface free energy. Therefore, after laser ablation, the generation of copper oxide further increases the surface wettability.

After heat treatment, the laser-ablated samples changed from hydrophilic to super-hydrophobic. According to the chemical composition test results, the carbon content increased on the laser- and heat-treated surfaces. This was caused by the adsorption of organic matter in the air by oxides on the surface of the copper plate. Since the main component of most organic molecules, alkyl, is nonpolar, adsorbing organic matter from the air is a more efficient way of reducing the surface polarity of copper oxide [30-32]. Various organic substances are adsorbed on the surface, thereby reducing the surface polarization, resulting in surface wettability transformation. In addition, cuprous oxide was formed after heat treatment. Cuprous oxide is insoluble in water and is a hydrophobic substance, which also affects the surface wettability to a certain extent [33]. Some researchers studied the relationship between material surface wettability and material surface microstructure [34]. In this study, the effect of laser parameters on the surface microstructure was investigated. According to Section 3.1, the best super-hydrophobic copper surface appeared with the lower laser scanning speed and smaller scanning interval. It is coincident with the Cassie state, where the rougher surface appears hydrophobic. The wettability of copper plates could be explained in three states: the Cassie state [35], the mixed wetting state [36-39], and the Wenzel state [29]. Firstly, when the laser energy is high or the scanning speed and the scanning interval are low, the surface shows super-hydrophobicity and low adhesion, which can be explained by the Cassie state, where $\theta_{\mathrm{r}}$ is the Cu surface APCA after laser treatment, $\theta$ is the contact angle, and $\mathrm{f}$ is the fractional interface area of the $\mathrm{Cu}$ surface, while $(1-f)$ stands for the drop-air contact area. Considering a contact angle of $180^{\circ}$, the calculation expression is shown in Equation (1) [40-43].

$$
\operatorname{Cos} \theta_{\mathrm{r}}=f \cos \theta+(1-f) \cos 180^{\circ}=f \cos \theta+f-1
$$

As shown in Figure 7, there is air remaining in the rough groove when water drops onto the surface. The trapped air in the groove prevents the water droplets from flowing into the groove. The material surface consists of two parts: the material solid slender bar and the trapped air. In this case, the actual contact area of the droplet includes both droplet-air contact and droplet-material solid slender bar contact. As can be seen from Equation (1), with the increase of roughness coefficient or surface hydrophobicity, the droplets become more stable on the rough surface; that is, the APCA becomes larger. When the scanning interval and scanning speed are small, the formed micro/nano-structure is dense and the surface roughness is large; thus, some of the water droplets contact the air, resulting in very low adhesion [40]. Then, as the scanning speed and the scanning interval increase, the micro/nano-structure becomes flat and shallow. At the same time, the rough nanostructures that form at the top of the microstructure gradually disappear and ripple, allowing water to partially enter the structure. This state is known as the mixed wetting state. In this state, the APCA changes relatively slightly; however, the WSA increases markedly. As the scanning speed and spacing increase further, the surface only produces some ripples and water fills the entire structure-a state known as the Wenzel state. Due to the large contact area between water droplets and the surface, there is increased adhesion. In this state, the APCA is relatively small, while the WSA is large. Therefore, the laser parameters have great influence on the WSA of the copper plate. Different surface wettability states can be obtained by adjusting laser parameters. 


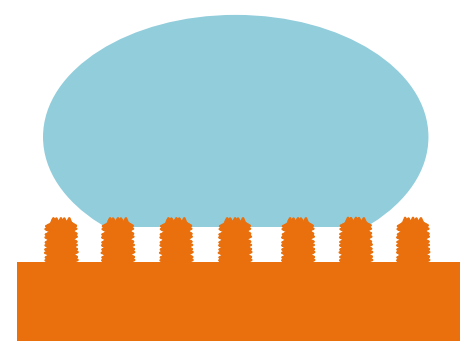

Figure 7. Cassie state.

\section{Conclusions}

A super-hydrophilic surface was fabricated on a copper plate using a nanosecond laser, and then transformed into a super-hydrophobic surface using a simple heat treatment. By controlling the scanning interval and scanning speed, different micro/nano-structures were fabricated on the copper surface. The wettability of different micro/nano-structures are varied when placing the sample in a heater at $150{ }^{\circ} \mathrm{C}$ for $2 \mathrm{~h}$, before slowly cooling to room temperature. The dense micro/nano-structure formed with the small scanning interval and scanning speed exhibited a large contact angle and a small sliding angle, characterizing it as super-hydrophobic. With the increase of scanning interval and scanning speed, the micro/nano-structure became flat, the APCA became smaller, and the WSA became larger. Obviously, different morphologies have significant effects on the wettability of the surface. The fine uniform ripples produced by the tiny redeposited nanoparticles have a strong adhesion to water. Through this work, the effects of laser processing parameters on the wettability of copper plates, as well as the influence of atmospheric storage temperature on the change of surface APCA with time, were clarified.

Author Contributions: Conceptualization, P.S. and J.Z.; methodology, J.G.; software, L.W. and C.D.; validation, J.Z.; formal analysis, C.L.; investigation, L.W.; writing-review and editing, L.M.; visualization, J.G.; supervision, J.Z.; project administration, J.Z.; funding acquisition, J.Z.

Funding: This research was funded by Tianjin Municipal Education Commission, China, grant number 2017KJ020" and Tianjin Municipal Science and Technology Commission, China, grant number 17JCYBJC42400.

Conflicts of Interest: The authors declare no conflict of interest.

\section{References}

1. Tadanaga, K.; Morinaga, J.; Matsuda, A.; Minami, T. Superhydrophobic superhydrophilic micropatterning on flowerlike alumina coating flm by the sol-gel method. Chem. Mater. 2000, 12, 590-592. [CrossRef]

2. Marmur, A.; Della Volpe, C.; Siboni, S.; Amirfazli, A.; Drelich, J.W. Contact Angles and Wettability: Towards Common and Accurate Terminology. Surf. Innovations 2017, 5, 3-8. [CrossRef]

3. Peng, S.; Bhushan, B. Mechanically durable superoleophobic aluminum surfaces with microstep and nanoreticula hierarchical structure for self-cleaning and antismudge properties. J. Colloid Interface Sci. 2016, 461, 273-284. [CrossRef] [PubMed]

4. Nishimoto, S.; Bhushan, B. Bioinspired self-cleaning surfaces with superhydrophobicity, superoleophobicity, and superhydrophilicity. RSC Adv. 2013, 3, 671-690. [CrossRef]

5. Shin, S.; Seo, J.; Han, H.; Kang, S.; Kim, H.; Lee, T. Bio-inspired extreme wetting surfaces for biomedical applications. Materials 2016, 9, 116. [CrossRef]

6. Fleming, R.A.; Zou, M. Fabrication of stable superhydrophilic surfaces on titanium substrates. J. Adhes. Sci. Technol. 2014, 28, 823-832. [CrossRef]

7. Melaibari, A.A.; Wu, Z.; Shrotriya, P.; Molian, P.; Bushlya, V.; Zhou, J.; Ståhl, J.E.; Petrusha, I. Extreme Hardness Achievements in Binderless Boron Nitride Tools. Acta Mater. 2016, 102, 315-322. [CrossRef]

8. Zorba, V.; Stratakis, E.; Barberoglou, M.; Spanakis, E.; Tzanetakis, P.; Anastasiadis, S.H.; Fotakis, C. Biomimetic artifcial surfaces quantitatively reproduce the water repellency of a lotus leaf. Adv. Mater. 2008, 20, 4049-4054. [CrossRef] 
9. Zhao, J.; Shrotriya, P. Increase the hardness of polycrystalline cubic/wurtzite boron nitride composite through Hybrid Laser/Waterjet Heat (LWH) treatment. Adv. Appl. Ceram. 2017, 6, 333-340. [CrossRef]

10. Rao, A.V.; Latthe, S.S.; Mahadik, S.A.; Kappenstein, C. Mechanically stable and corrosion resistant superhydrophobic sol-gel coatings on copper substrate. Appl. Surf. Sci. 2011, 257, 5772-5776. [CrossRef]

11. Zhao, J.; Wong, K.S.; Shrotriya, P. Hybrid $\mathrm{CO}_{2}$ laser waterjet heat (LWH) treatment of bindered boron nitride composites with hardness improvement. Ceram. Int. 2017, 43, 8031-8039. [CrossRef]

12. Crick, C.R.; Bear, J.C.; Kafzas, A.; Parkin, I.P. Superhydrophobic photocatalytic surfaces through direct incorporation of titania nanoparticles into a polymermatrix by aerosol assisted chemical vapor deposition. Adv. Mater. 2012, 24, 3505-3508. [CrossRef] [PubMed]

13. Ruan, M.; Li, W.; Wang, B.; Deng, B.; Ma, F.; Yu, Z. Preparation and anti-icing behavior of superhydrophobic surfaces on aluminum alloy substrates. Langmuir 2013, 29, 8482-8491. [CrossRef] [PubMed]

14. Liu, Y.; Yin, X.; Zhang, J.; Wang, Y.; Han, Z.; Ren, L. Biomimetic hydrophobic surface fabricated by chemical etching method from hierarchically structured magnesium alloy substrate. Appl. Surf. Sci. 2013, 280, 845-849. [CrossRef]

15. Sung, Y.H.; Kim, Y.D.; Choi, H.J.; Shin, R.; Kang, S.; Lee, H. Fabrication of superhydrophobic surfaces with nano-in-micro structures using UV-nanoimprint lithography and thermal shrinkage films. Appl. Surf. Sci. 2015, 349, 169-173. [CrossRef]

16. Chen, Z.; Hao, L.; Chen, A.; Song, Q.; Chen, C. A rapid one-step process for fabrication of superhydrophobic surface by electrode position method. Electrochim. Acta 2012, 59, 168-171. [CrossRef]

17. Zhao, Y.; Li, M.; Lu, Q.; Shi, Z. Superhydrophobic polyimide films with a hierarchical topography: Combined replica molding and layer-by-layer assembly. Langmuir 2008, 24, 12651-12657. [CrossRef]

18. Zhao, J.; Guo, J.; Shrotriya, P.; Wang, Y.; Han, Y.; Dong, Y.; Yang, S. A rapid one-step nanosecond laser process for fabrication of superhydrophilic aluminum surface. Opt. Laser Technol. 2019, 117, 134-141. [CrossRef]

19. Chen, F.; Zhang, D.; Yang, Q.; Yong, J.; Du, G.; Si, J.; Yun, F.; Hou, X. Bioinspired wetting surface via laser microfabrication. ACS Appl. Mater. Interfaces 2013, 5, 6777-6792. [CrossRef]

20. Vorobyev, A.Y.; Guo, C. Direct femtosecond laser surface nano/microstructuring and its applications. Laser Photon. Rev. 2013, 7, 385-407. [CrossRef]

21. Jagdheesh, R.; Pathiraj, B.; Karatay, E.; Romer, G.R.B.E.; Huis in't Veld, A.J. Laser-induced nanoscale superhydrophobic structures on metal surfaces. Langmuir 2011, 27, 8464-8469. [CrossRef] [PubMed]

22. Bricchi, E.; Klappauf, B.G.; Kazansky, P.G. Form birefringence and negative index change created by femtosecond direct writing in transparent materials. Opt. Lett. 2004, 29, 119-121. [CrossRef] [PubMed]

23. Athanasiou, C.E.; Bellouard, Y. A monolithic micro-tensile tester for investigating silicon dioxide polymorph micromechanics, fabricated and operated using a femtosecond laser. Micromachines 2015, 6, 1365-1386. [CrossRef]

24. Zheng, B.; Jiang, G.; Wang, W.; Mei, X. Fabrication of superhydrophilic or superhydrophobic self-cleaning metal surfaces using picosecond laser pulses and chemical fluorination. Radiat. Eff. Defects Solids 2016, 171, 461-473. [CrossRef]

25. Chang, F.M.; Cheng, S.L.; Hong, S.J.; Sheng, Y.J.; Tsao, H.K. Superhydrophilicity to superhydrophobicity transition of CuO nanowire films. Appl. Phys. Lett. 2010, 96, 114101. [CrossRef]

26. Ta, D.V.; Dunn, A.; Wasley, T.J.; Kay, R.W.; Stringer, J.; Smith, P.J.; Connaughton, C.; Shephard, J.D. Nanosecond laser textured superhydrophobic metallic surfaces and their chemical sensing applications. Appl. Surf. Sci. 2015, 357, 248-254. [CrossRef]

27. Long, J.; Zhong, M.; Fan, P.; Gong, D.; Zhang, H. Wettability conversion of ultrafast laser structured copper surface. J. Laser Appl. 2015, 27, S29107. [CrossRef]

28. Long, J.; Zhong, M.; Zhang, H.; Fan, P. Superhydrophilicity to superhydrophobicity transition of picosecond laser microstructured aluminum in ambient air. J. Colloid Interface Sci. 2014, 441, 1-9. [CrossRef]

29. Wenzel, R.N. Resistance of solid surfaces to wetting by water. Ind. Eng. Chem. 1936, 28, 988-994. [CrossRef]

30. Kietzig, A.M.; Hatzikiriakos, S.G.; Englezos, P. Patterned Superhydrophobic Metallic Surfaces. Langmuir 2009, 25, 4821-4827. [CrossRef]

31. Li, Z.; Zheng, Y.; Zhao, J.; Cui, L. Wettability of Atmospheric Plasma Sprayed Fe, Ni, Cr and Their Mixture Coatings. J. Therm. Spray Technol. 2012, 21, 255-262. [CrossRef]

32. Azimi, G.; Dhiman, R.; Kwon, H.M.; Paxson, A.T.; Varanasi, K.K. Hydrophobicity of rare-earth oxide ceramics. Nat. Mater. 2013, 12, 315-320. [CrossRef] [PubMed] 
33. Chun, D.M.; Ngo, C.V.; Lee, K.M. Fast fabrication of superhydrophobic metallic surface using nanosecond laser texturing and low-temperature annealing. CIRP Ann. 2016, 65, 519-522. [CrossRef]

34. Song, Y.; Wang, C.; Dong, X.; Yin, K.; Zhang, F.; Xie, Z.; Chu, D.; Duan, J.A. Controllable superhydrophobic aluminum surfaces with tunable adhesion fabricated by femtosecond laser. Opt. Laser Technol. 2018, 102, 25-31. [CrossRef]

35. Cassie, A.B.D.; Baxter, S. Wettability of porous surfaces. Trans. Faraday Soc. 1944, 40, 546-551. [CrossRef]

36. Patankar, N.A. On the modeling of hydrophobic contact angles on rough surfaces. Langmuir 2003, 19, 1249-1253. [CrossRef]

37. Feng, X.; Jiang, L. Design and creation of superwetting/antiwetting surfaces. Adv. Mater. 2006, 18, $3063-3078$. [CrossRef]

38. Miwa, M.; Nakajima, A.; Fujishima, A.; Hashimoto, K.; Watanabe, T. Effects of the surface roughness on sliding angles of water droplets on superhydrophobic surfaces. Langmuir 2000, 16, 5754-5760. [CrossRef]

39. Marmur, A. Wetting on hydrophobic rough surfaces: To be heterogeneous or not to be? Langmuir 2003, 19, 8343-8348. [CrossRef]

40. Cheng, Z.; Du, M.; Lai, H.; Zhang, N.; Sun, K. From petal effect to lotus effect: A facile solution immersion process for the fabrication of super-hydrophobic surfaces with controlled adhesion. Nanoscale 2013, 5, 2776-2783. [CrossRef]

41. Herminghaus, S. Roughness-induced non-wetting. Europhys. Lett. 2000, 52, 165-170. [CrossRef]

42. Nosonovsky, M. Multiscale Roughness and Stability of Superhydrophobic Biomimetic Interfaces. Langmuir 2007, 23, 3157-3161. [CrossRef] [PubMed]

43. Bormashenko, E.; Stein, T.; Whyman, G.; Pogreb, R.; Sutovsky, S.; Danoch, Y.; Shoham, Y.; Bormashenko, Y.; Sorokov, B.; Aurbach, D. Superhydrophobic Metallic Surfaces and Their Wetting Properties. J. Adhes. Sci. Technol. 2008, 22, 379-385. [CrossRef]

(C) 2019 by the authors. Licensee MDPI, Basel, Switzerland. This article is an open access article distributed under the terms and conditions of the Creative Commons Attribution (CC BY) license (http://creativecommons.org/licenses/by/4.0/). 